\title{
Identification of an effective nondestructive technique for bond defect determination in laminate composites - a technical review
}

\author{
Muhammad Asif ${ }^{1,2 *}$, Muhammad Ali Khan ${ }^{3}$, Sohaib Zia Khan ${ }^{1,4}$, Rizwan Saeed Choudhry ${ }^{5}$, \\ Kamran A Khan ${ }^{6}$ \\ ${ }^{1}$ Department of Engineering Sciences, PN Engineering College, National University of Sciences and \\ Technology, Karachi, Pakistan \\ ${ }^{2}$ Department of Mechanical Engineering, Auckland University of Technology (AUT), New Zealand \\ ${ }^{3}$ Fatigue and Damage Tolerance, Through-life Engineering Services Institute. Cranfield University \\ United Kingdom. \\ ${ }^{4}$ Department of Mechanical Engineering, Faculty of Engineering, Islamic University of Madinah, \\ Madinah, PO Box 170, Kingdom of Saudi Arabia \\ ${ }^{5}$ Department of Mechanical Engineering, University of Bath, Bath, UK \\ ${ }^{6}$ Department of Aerospace Engineering, Khalifa University, PO Box 127788, Abu Dhabi, UAE \\ *Corresponding author: muhammad.asif@aut.ac.nz
}

\begin{abstract}
Laminate composites are commonly used for the production of critical mechanical structures and components such as wind turbine blades, helicopter rotors, UAV wings and honeycomb st ructures for aircraft wings. During the manufacturing process of these composite structures, $\mathrm{z}$ ones or areas with weak bond strength are always an issue which may affect the strength and $p$ erformance of components. The identification and quantification of these zones are always ch allenging and necessary for the mass production. Non-destructive testing (NDT) methods avai lable, including ultrasonic A, B, and C-Scan, laser shearography, X-ray tomography and ther mography can be useful for the mentioned purposes. However, a comparison of these techniq ues concerning their capacity of identification and quantification of bond defect still needs a comprehensive review.
\end{abstract}

In this paper, a detailed comparison of several NDT techniques is provided. Emphasis is placed to institute a guideline to select the most suitable technique for the identification of zones with bond defects in laminated composites. A literature review of NDT techniques informs us that the ultrasonic-based testing techniques are more effective for providing bond defect information as compared to their non-ultrasonic counterparts. Experimental tests on different 
composite based machined components are also discussed in detail. In comparison to other techniques, the discussion provides practical evidence about the effectiveness of the ultrasonic technique.

Keywords: NDT; Laminate; Composites; Weak Bonds; Defects; shearography

\section{INTRODUCTION}

Advanced composite laminates are the commonly used in the aeronautical and space applications. The main reasons to select these materials in these applications include excellent mechanical properties (strength and stiffness), ability to tailor them according to design requirement and low density compared to metals [1]. Advance composite structures possess several advantages compared to conventional materials. Some of the common benefits of the composite materials include its light weight; composites materials are $30 \%$ lighter compared to steel parts possessing same thermo-mechanical properties, high strength, low production cost; it can be manufactured by a range of processes and resistance to corrosion it provides excellent resistance to complex chemical and temperature environments.

Composite materials have a wide variety of applications ranging from construction to aerospace structure [2]. Different failure mechanisms in fiber-reinforced composites can lead to the composite structure property degradation such as breaking of fibers, debonding of fibers, delaminations, and matrix microcracks [3]. Fatigue delamination is also one of the primary failure modes in carbon fiber reinforced plastic (CFRP), and extensive research has been conducted on this topic [4-14]

All composite structures are subjected to defects which affect the mechanical performance, and these defects are likely to increase in frequency with structural integrity. Defects are observed both during manufacturing process where if detected they are repaired and during service. Constituent composite materials can carry manufacturing induced flaws, also at different interfaces of the resultant structure [15]. Adhesively bonded joints are subjected to three main type of defects: (a) disbands or porosity (b) reduced adhesion resulting from weak bonding between the adhesive and adherend and (c) poor cohesiveness resulting from the weak cohesive layer. Extensive research has been conducted to develop NDT techniques to evaluate the adhesive bond quality and to test its integrity [16-24]. During the manufacturing process, physical discontinuities can appear easily in bonded joints. Mechanical performance and structural strength of bonded structures and/or composites can significantly be affected by the 
presence and development of such defects [16]. Conventional ultrasonic techniques typically fail to detect poor adhesion between adhesive and adherend. Some researchers have tried to evaluate composite-to-composite adhesive joints [25-28].

Kissing bonds or zero volume bonds are defined as defects in which both surfaces are bonded together by compressive stress having zero molecular force acting upon them. If both surfaces are joined in such a manner that there is no shear stress between them, it is referred to as kissing bond [29]. A significant amount of literature is available on kissing bonds [30-35]. Attempts are being made to evaluate kissing bonds particularly utilizing advanced ultrasonic techniques like non-linear acoustics, which proved highly effective [35-39]. To assess the joint/bond integrity and the structural health state, in recent years, considerable amount of work has been done to develop effectively and on time non-destructive evaluation techniques [40].

\section{NONDESTRUCTIVE TESTING}

Nondestructive testing (NDT) techniques are commonly used to evaluate the condition of the structure including composites. NDT is aimed to (a) detect delamination or variation of the properties in the materials (b) provide useful information based on given material properties in different areas of a structure (c) to compare them to allowable limitations [41]. Different nondestructive techniques are available, such as ultrasonic testing and X-rays, for the detection of discontinuities like pores, delamination, debonding, cracks, voids, porosity and other defects [42-51]. The existing literature cites a considerable amount of work about methods developed for the Nondestructive evaluation (NDE) in composites and bonded joints. Methods such as ultrasonic testing, low-frequency vibration, infrared thermography, leak test, acoustic emission and shearography are commonly used [52].

Researchers are keen in establishing and improving NDT methods which can monitor the quality of the products during manufacturing processes [53], material soundness when transporting [54], storage and fabrication [55] and amount and rate of in-service degradation [56]. Moreover, attempts are being made to establish new NDT methods which have the capacity of determining the discontinuity of the defects quantitatively [57, 58].

Researchers and industrialist are using NDT techniques such as ultrasonic, laser shearography and thermography for the bond defect identification. Suitability analysis of these techniques concerning the possible application of composites is essential for a cost-effective identification. 
Owing to a lack of comparative studies for the suitability, a comprehensive investigation is still required for the selection of a feasible NDT technique.

Thus, in this research, a detailed comparison of several NDT techniques is provided. It can be used to establish a baseline in the selection of the most suitable technique for the identification of zones with bond defects. It has been found that the ultrasonic-based testing techniques are more effective for yielding bond defect information as compare to their non-ultrasonic counterparts. Tests on different composite based machine components are also discussed in the present work.

\section{APPLICATION OF NDT TECHNIQUES IN BOND DEFECT IDENTIFICATION}

\subsection{Ultrasonic Techniques}

Ultrasonic testing is the most commonly used nondestructive method for the inspection of the composites. During the inspection, it commonly utilizes the frequency ranging from $20 \mathrm{kHz}$ to $20 \mathrm{MHz}$. Typically, energy pulses of ultrasound few microseconds are sent into the object and evaluated after cross-examining the structure [59]

\subsubsection{Pulse Echo}

Ultrasonic pulse echo is commonly used and advantageous nondestructive testing method. Ideally few microsecond's ultrasonic energy pulse is sent into the object with the direction normal to the surface. Boundaries associated with good matrix reinforcement and flaws reflects the pulse. Probe detects the signal which travels back in its direction, and amplitude detected and total pulse travel time helps in determining the position and size of flaw. This is called Ascan consisting of series of peaks, whose horizontal axis position can be calibrated in terms of the depth in the object. The amplitude of the each can be used to obtain useful information about the size and nature of the reflector, which can be either a flaw or a specimen boundary. In 'B-scan' display probe is scanned along the surface to produce $2 \mathrm{D}$ 'slice' through the specimen, and A-scan is captured at each point along the scanning direction. In 'D-scan' specimen is also sliced through which is received in each of a set of parallel B-scans at fixed scanning point. 'Top-down' or 'Plain' views of the component are taken in C-scans. In this display, either the amplitude or the signals depth occurring within the predefined depth range within the component does gating on A-scan. Pulse-echo technique is used more frequently due to its advantages such as safety and reliability, inspection can be carried out on only one 
side of the structure, and the instrumentation can be portable [60]. Figure 1 displays a submerged immersion test setup for a conventional pulse echo.

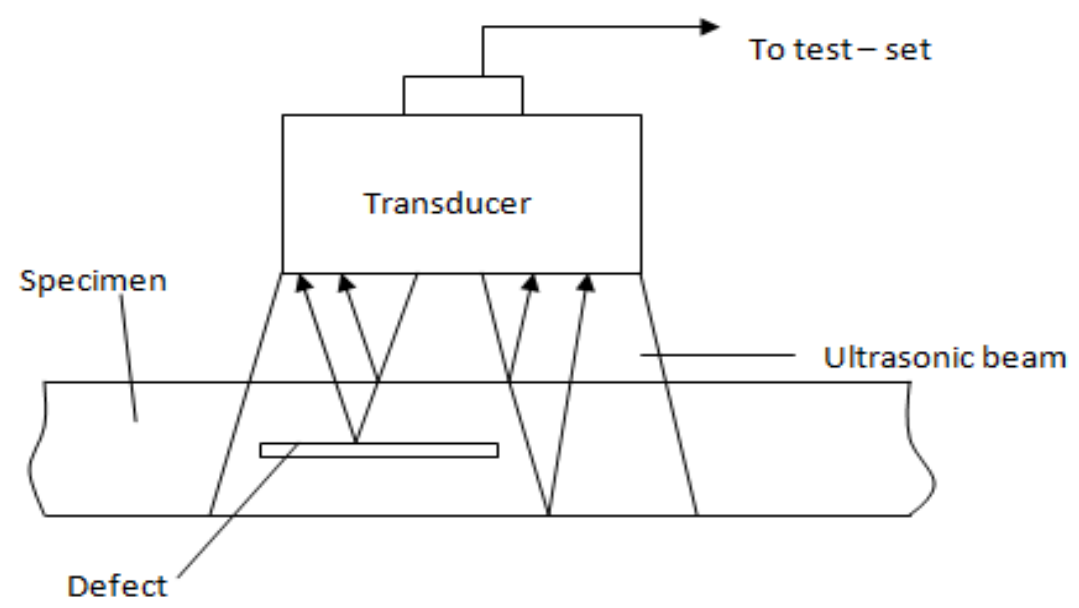

Figure 1. Submerged specimen with Immersion pulse-echo test setup

The position and size of the flaw are determined by detecting the signals which travel back in the direction of the probe, total pulse travel time and amplitude.

\subsubsection{Through Transmission}

Through transmission utilizes two transducers: one emitter and one receiver. The receiver is put on the opposite side of the component facing the transmitting probe. It is also called obstruction method due to the reason it calculates total attenuation of the material done by feature responsible for obscuring the beam.

Figure 2 shows the setup of through transmission immersion test in the jet probe. A jet of water projected unto its surface is used to couple ultrasound to the specimen. 


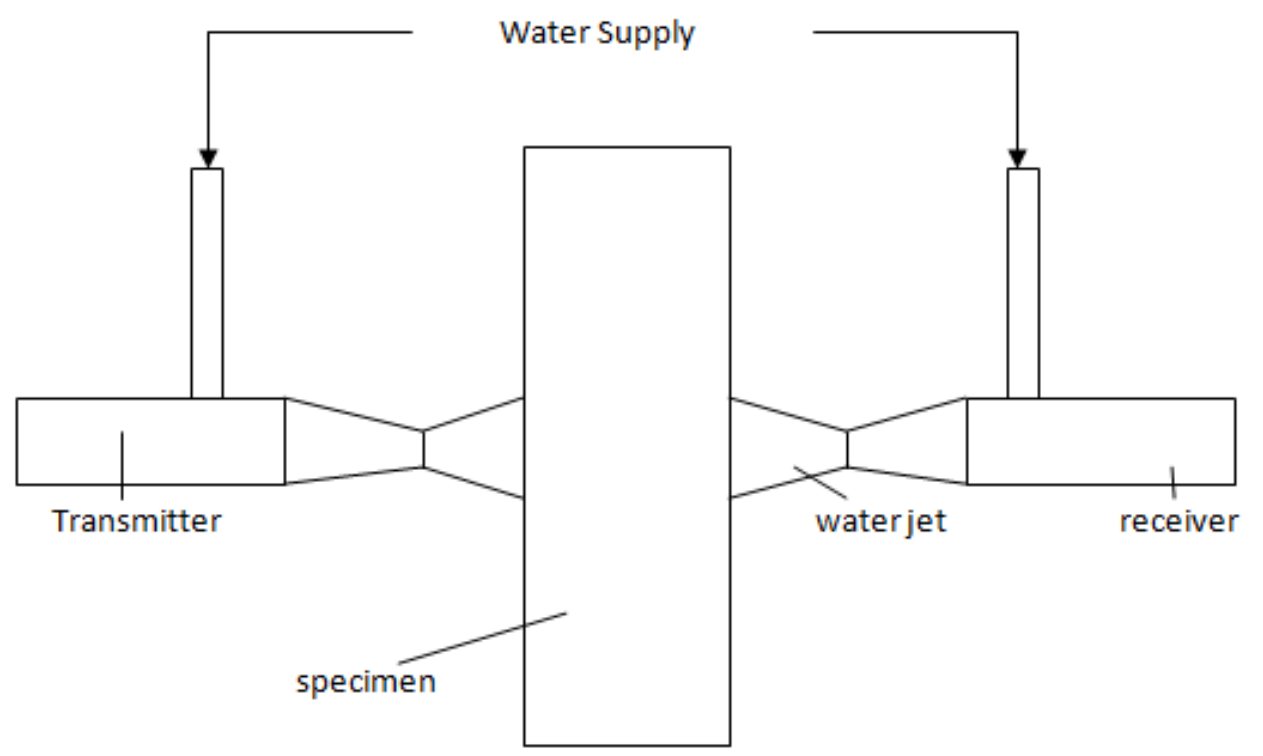

Figure 2. Through transmission immersion test setup using jet probes.

Through transmission is used to produce $\mathrm{C}$ scans attenuation which helps in deterring common discontinuities which include delamination, porosity and some inclusions [52]. Although this method gives accessible and useful ways of weak bond identification in bonded joints, it is tough to access automotive joints from both sides at the same time [61].

\subsubsection{Guided Waves}

Guided or traveling wave: Raleigh, Lamb and interface waves, all these waves propagate in the plane. They have the advantage of traveling long distances which enables in interrogating a line rather than point [61]. Interaction of guided waves with bonded objects now includes interfacial conditions between bonded objects $[18,62]$. Lamb waves proposed to be an effective technique for investigating contact conditions in bonded joints [63-67]

Guided waves proved to be a great technique in SHM applications to investigate flaws in platelike objects. They have the advantage of traveling long distances covering large areas with utilizing a confined number of sensors. Since it investigates entire thickness, makes it possible to disclose flaws inside the object, which are cracks and delaminations and also on the surface, i.e., corrosion [68]. Guided waves can provide handful experimental information to investigate the bond strength of mechanical joints in objects [69]. 


\subsubsection{Electromagnetic Acoustic Transducer (EMAT)}

Electromagnetic Acoustic Transducer (EMAT) is different from traditional ultrasonic techniques. In this technique, the sound is created in the object under consideration. An EMAT made of a magnet and coil of wire generates an acoustic wave within the material itself utilizing Lorentz forces and magnetostriction. EMAT is couplant free, which makes it helpful for automated, quick and inline inspection usage.

EMATs are commonly used nowadays for contact-free NDT of metals. Ultrasound can be generated and detected in either non-magnetic metal like aluminum or magnetic like ferrous steels and also by either utilizing Lorentz force principle (metals) or magneto-elastic effects in non-conducting magnetic materials [70-75].

Using two interacting magnetic fields, EMAT induces ultrasonic waves into test object as shown in Figure 3. Electrical coils generate high frequency (RF) field which interacts with low frequency or static field produced by magnets to develop the wave on the surface of the test specimen. Shear waves horizontal polarization (SH waves) can only be generated by EMATs which don't travel through low-density couplants [76]. Presently this technique is used more frequently because it can generate ultrasonic waves in metals directly [77].

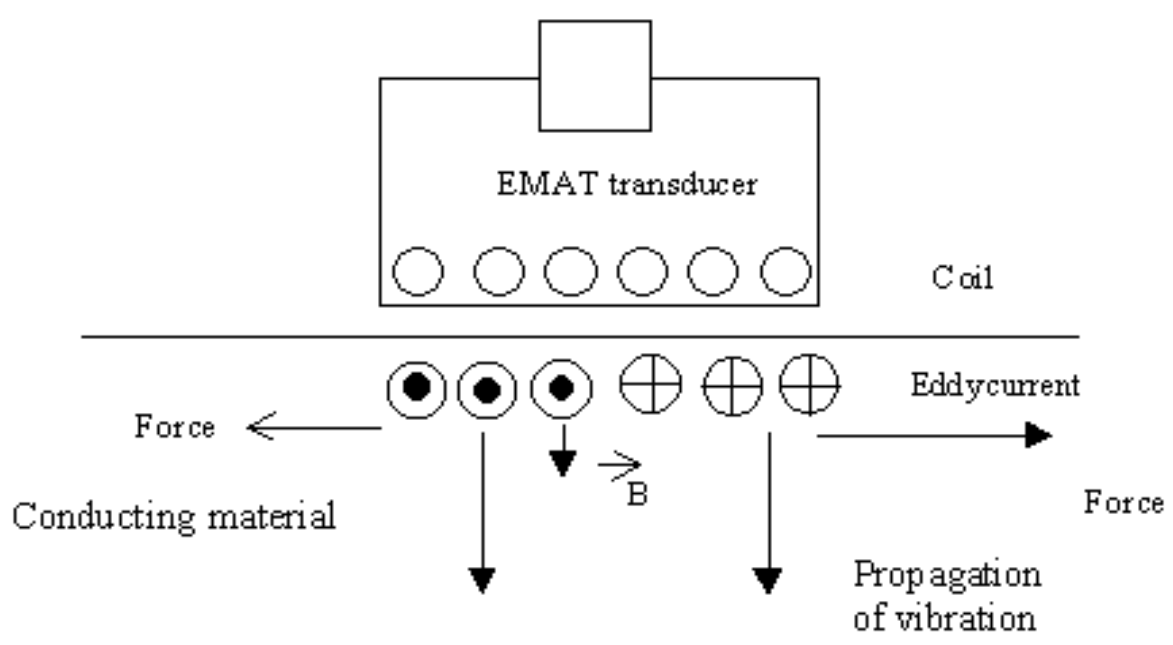

Figure 3. EMAT Ultrasonic inspection technique [78] 


\subsection{Non-Ultrasonic Techniques}

The advancement in the non-ultrasonic techniques in recent years has increased in the usage for detecting flaws, delaminations, and discontinuities in the materials. Non-ultrasonic techniques such as shearography and thermography are discussed below.

\subsubsection{Shearography}

Shearography is the most reliable method having the ability of rapid NDT \& E as well as computable analysis of stresses, strains, vibrations etc. [79-85]. Phase shifting technique can help in enhancing the efficiency and reactivity in flaw detection and strain analysis [86, 87]. As compared to conventional NDT methods, shearography reveal a flaw in a structure by revealing flaw - induced deformation anomalies. Those flaws are more related to structural instability $[88,89]$.

The optical setup of a shearography technique relevant for the analysis of out-of-plane displacement gradient is displayed in Figure 4. The laser output is enlarged to highlight the place of importance of the surface of the structure under examination. The dispersed light forms a laser speckle arrangement which is observed through a Michelson shearing interferometer onto a CCD camera. The purpose of the shearing device is to break the image so that the CCD camera reports two similar but displaced illustrations. Interferometric speckle pattern at the sensor of the camera is developed by combining the two illustrations coherently.

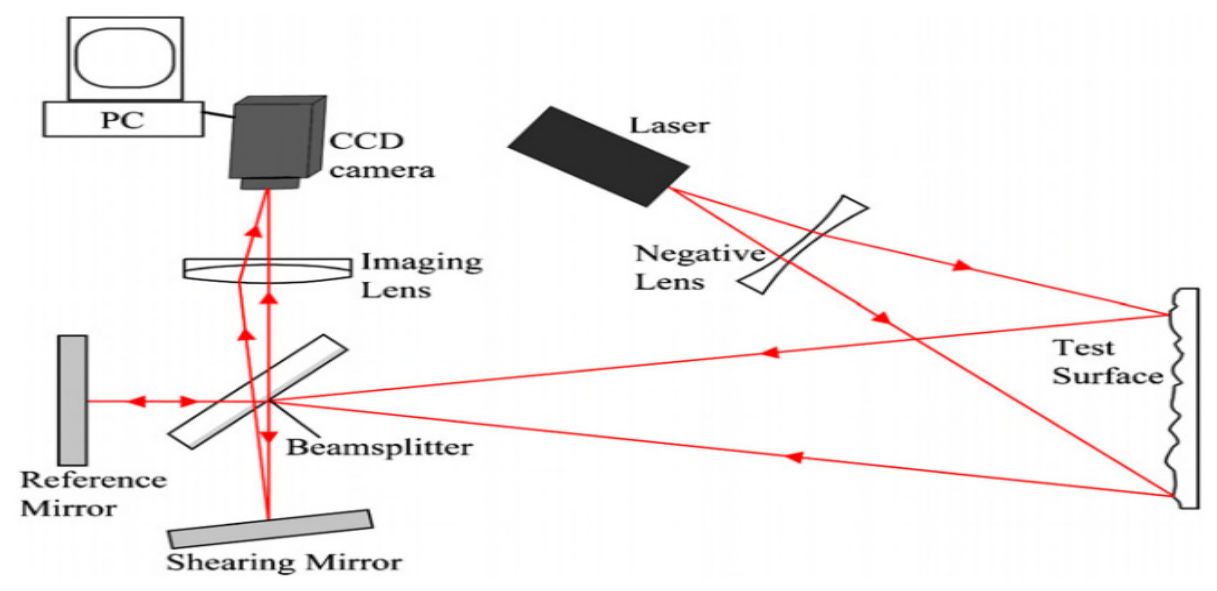

Figure 4. Michelson shearing interferometer based shearing system [90]

The light adding to each speckle in the arrangement is dispersed from points on the specimen's surface detached by the shear distance. Any noticeable dislocation of the surface will provide a phase variation difference among the light dispersed from the points responsible for the 
change in depth of each speckle. Comparing images observed before and after some loading, generally by digital deduction and modification, provides a fringe pattern where the fringes serve as a locus of points with the same magnitude of displacement gradient [90].

\subsubsection{Thermography}

Thermography utilizes infrared cameras which are costly, but other characteristics suitable; especially, the thermal field of the sample can be attained in full out of which outside and inside defects can be investigated by using adapted software [91].

Zhang et al. [92] in their article on a review of optical NDT technologies states that infrared thermography is the measure of the difference in the temperature. Active and passive are the two kinds of thermography. Active thermography (AT) can be explained as using a stimulus to an object of interest that causes the object to heat or cold. It grants the attributes of the object to be analyzed under the camera of thermal imagery [93-100]. Passive thermography (PT) can be explained as calculating the difference in temperature among the objects of interest of the surroundings under different conditions of ambient temperature. Implemented infrared thermography methods are active methods. Active thermography has further subtypes as Pulsed Thermography (PT), Pulsed-Phase Thermography (PPT) and Modulated Thermography (MT). Figure 5 shows an example of PPT.

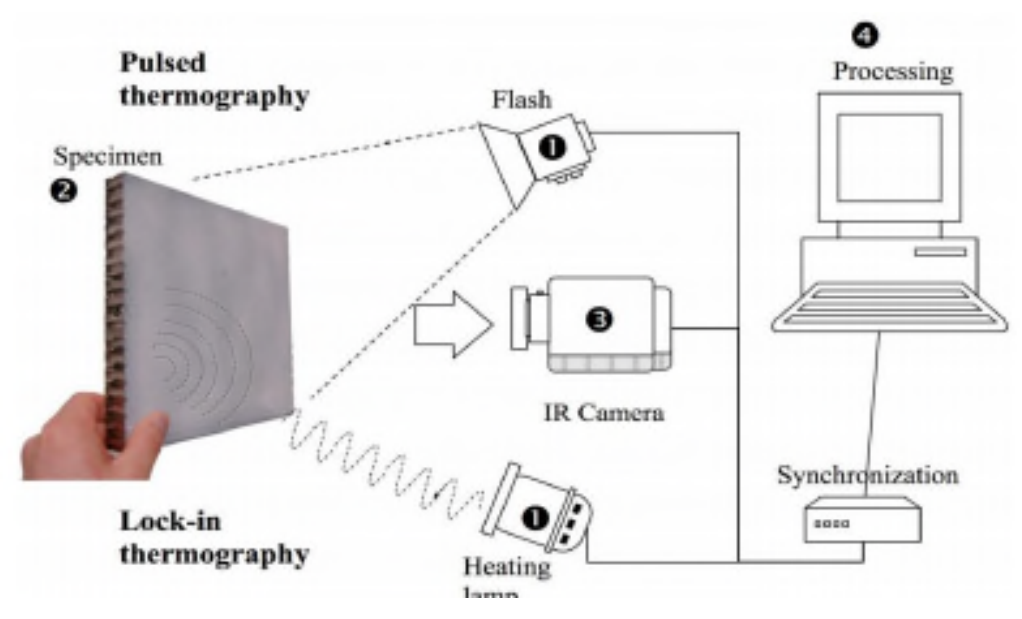

Figure 5. Two pulsed thermography and lock-in thermography [92]

\section{EXPERIMENTAL TESTS}

The suitability of various NDT techniques is proven for detecting bond defects in composite materials. Different tests and experiments have been performed, and a brief detail is provided here. 


\subsection{ULTRASONIC TECHNIQUES}

\subsubsection{Pulse Echo}

Duvall et al. tested the suitability of ultrasonic methods based on pulse echo and through transmission on bond defects [101]. They created the bond defects using adhesives applied in the automotive industry. It was achieved by manufacturing a number of lap joint coupons which were developed by using two galvanized steel adherends having 1-inch overlap and having a bond area of 1" x 1". Steel and the standard bond line had a thickness of $1.5 \mathrm{~mm}$ and $0.40 \mathrm{~mm}$ respectively. The coupons were made according to the specific methods designed to produce different stages of bond defects. To develop interface property changes in the surface of the steel and adhesive layer, different contaminants were used at a side of steel plate in the lap slice overlap region.

The tensile strength of the specimens was investigated by conducting the tensile test on the uniaxial machine. Results from the tests were used to study the difference in the strength and full bond strength percentage for each of specific bond defect method. To compare tensile strength and divergence results number of coupons were developed similar to the weak bond method. The weak bond method was showing minimum divergence in tensile strength results were put into a percentage of full strength bin, i.e., $10 \%, 30 \%$, and $50 \%$. 10\%, 30\%, 50\%, $70 \%$ and $90 \%$. Were the final percentage of full strength bins used.

Pulse-echo technique is also beneficial for detecting the bond strength and can provide handful details utilizing C-scan images developed by using some custom signal analysis. Through study on pulse-echo ultrasonic successfully illustrated the fractions of the signal that had the primary bond strength detail. Figure 6 shows the results of the weak bond specimen; it can be seen that echoes associated with bond such as 3,5 and 6 are reduced as the bond strength decreases. Thus by calculating the ratios between the amplitude of echo 2 and echo 3, the bond strength can be determined for an array of the specimen. Table 1 shows the results using this calculation and outlines that the UT peak signal measurements are close for $60-90 \%$ bond strength but can differentiate bonds that are less than $50 \%$ (S/N results are high enough to produce consistent results) 

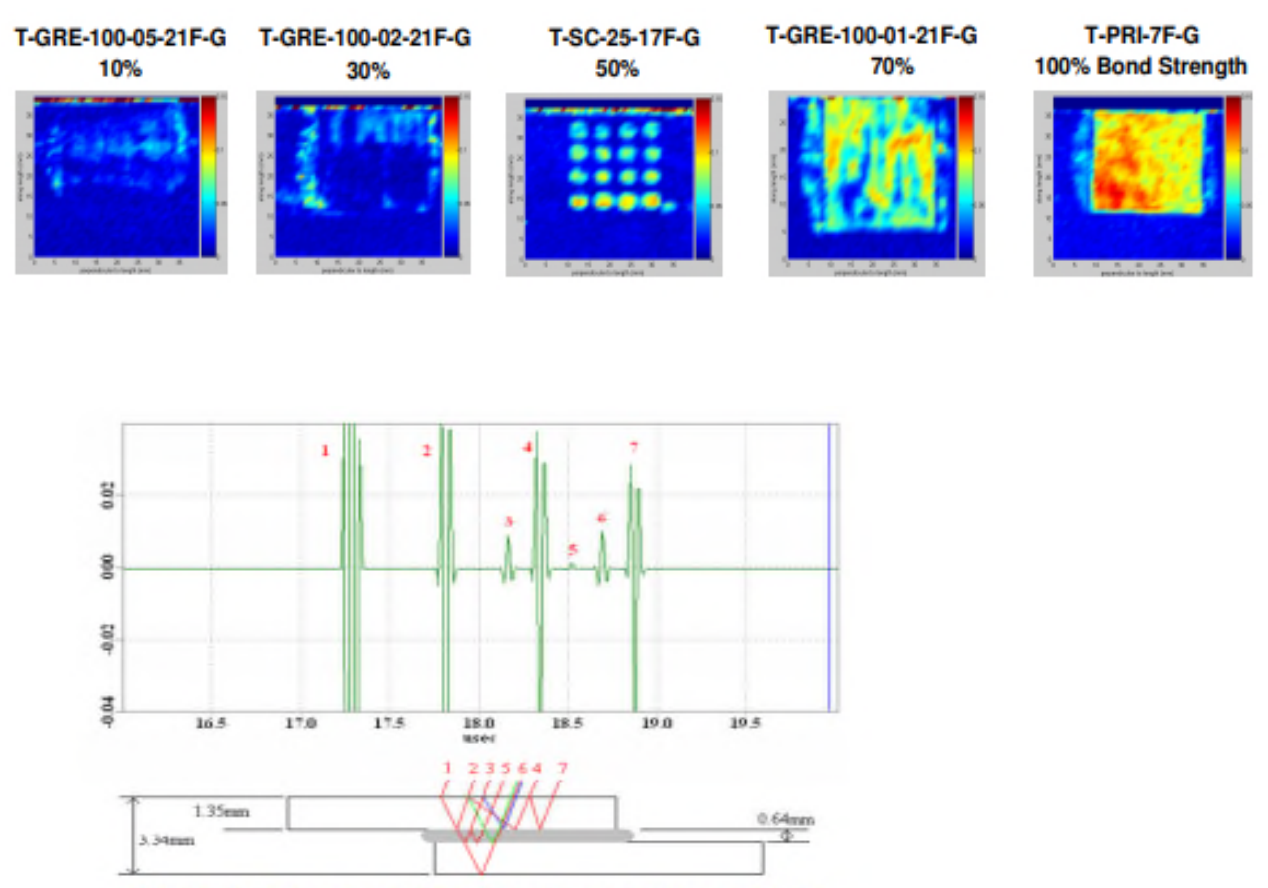

Peak 3 interrogates the bond line and is critical to producing sensitive assessments

Figure 6. Pulse Echo UT Inspection [101].

Table 1: Weak bond determination utilizing ratio of peak 2 and peak 3 amplitudes [101].

\begin{tabular}{|c|c|c|}
\hline Sample & Bond Strength \% & Amplitude E3/amplitude \\
& & 0.096 \\
\hline T-PRI-7F-G & 100 & 0.085 \\
\hline T-MO-RE-MS-25-17F & 88 & 0.087 \\
\hline T-GRE-100-01-21F-G & 62 & 0.097 \\
\hline T-MO-RE-MS-50-18F-G & 58 & 0.024 \\
\hline T-PWD-10-21F & 46 & 0.016 \\
\hline T-SC-25-17F-G & 46 & 0.042 \\
\hline T-PWD-25-21F-G & 31 & 0.014 \\
\hline T-GRE-100-05-21F-G & 26 & 0.006 \\
\hline T-GRE-100-05-21F-G & 11 & 0.01 \\
\hline T-PWD-100-19F-G & 10 & \\
\hline
\end{tabular}




\subsubsection{Through Transmission}

Bond defects were successfully identified by using transmission ultrasonic technique. Figure 7 represents a number of plotted amplitudes along showing the bond strength of each of the specimens in the weak bond set. It is observed form the results that the physics of the changing bond affects the signal amplitude. The resulting c-scan images can be seen in Figure 8 in which overall brightness of C-scan darkens as the bond becomes weaker (decrease in amplitude) [101].

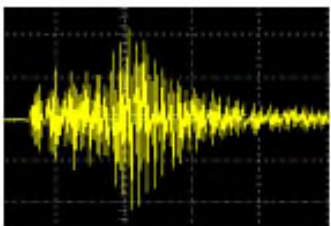

T-PRI-11F-E (100\%)

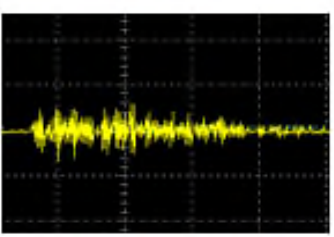

T-PWD-10-15F-E (50\%)

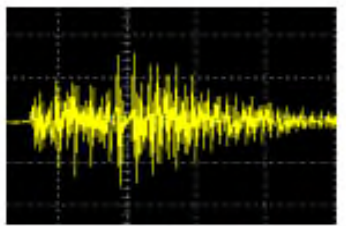

T-MO-RE-MS-25-11F-E $(90 \%)$

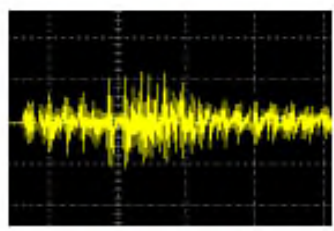

T-SC-25-11F-E

$(50 \%)$

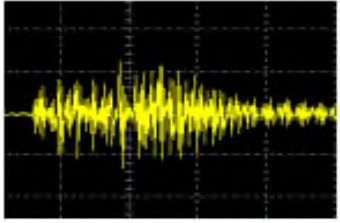

T-GRE-100-01-15F-E $(70 \%)$

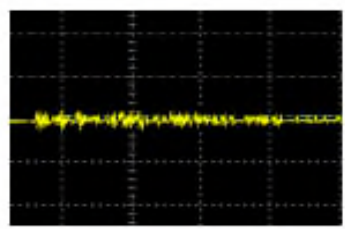

T-GRE-100-02-15F-E $(30 \%)$

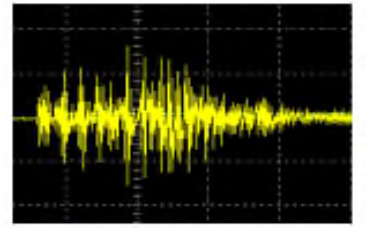

T-MO-RE-MS-50-12F-E $(70 \%)$

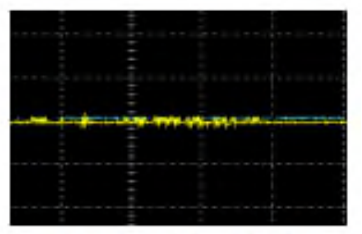

T-GRE-100-05-15F-E (10\%)

Figure 7. Ultrasonic A-Scans using Through Transmission Representing Reduction in the Amplitude as Bond Strength Decreases (Percentage below Indicates Bond Strength) [101]

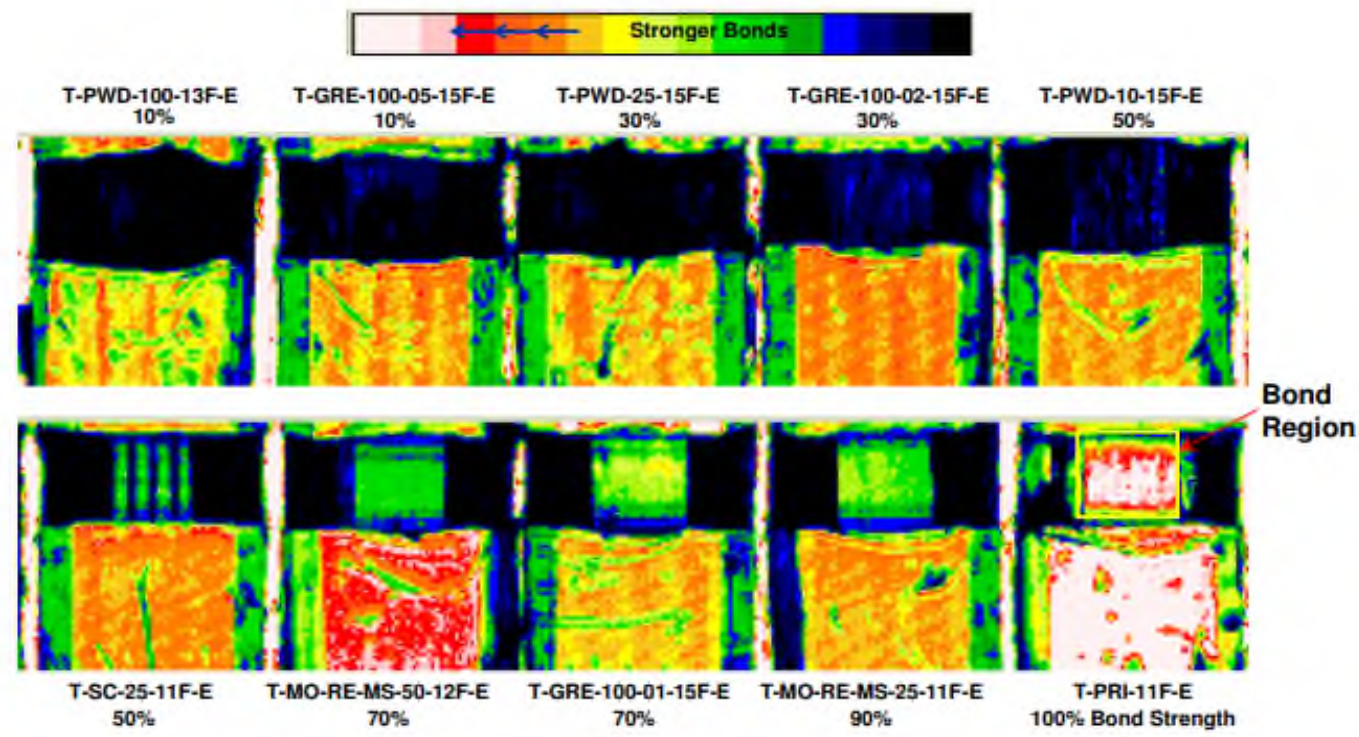

Figure 8: Bond strength determination using through transmission ultrasonic images [101] 


\subsubsection{Guided Wave EMATs}

Ultrasonic guided wave EMAT is used to test the bond defects in the aluminum tin/ alloy bimetal. For thin plate and surface inspection guided wave is a natural fit. Rather than facing a problem with very high equipment in the normal beam test, guided wave test can be performed at relatively low-frequency high signal to noise ratio. Guided wave modes that proved sensitive to bonding quality can be used for the inspection. EMAT is an ultrasonic testing technique having high repeatability and reliability and suitable for automation. Instead of struggling with the variation caused by couplant thickness and temperature, the sound is generated by the EMAT transducers on the surface of aluminum/tin alloy. The process is couplant free. The inspection is capable of meeting the production throughput speed of 8-15 meters per minute. Guided waves can be used to cover a width of $100 \mathrm{~mm}$ or more pending detailed theoretical experimental analysis. The full material width can be covered with one or few channels without a raster scan

Guided Wave EMAT test was conducted on few samples after peel test as shown in Figure 9. The sample 1237 is relatively large and good bonding is shown by the chisel and peel test results in the area close to the edge while the center of the plate is poor bonding or debonding.

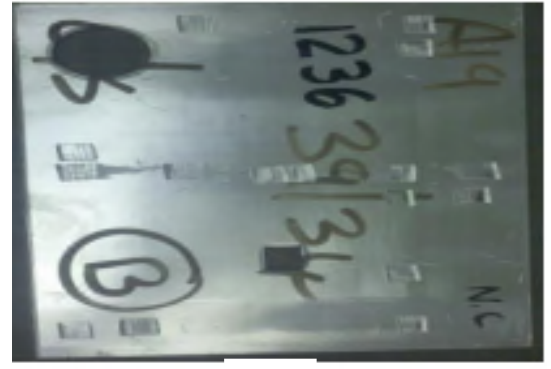

a

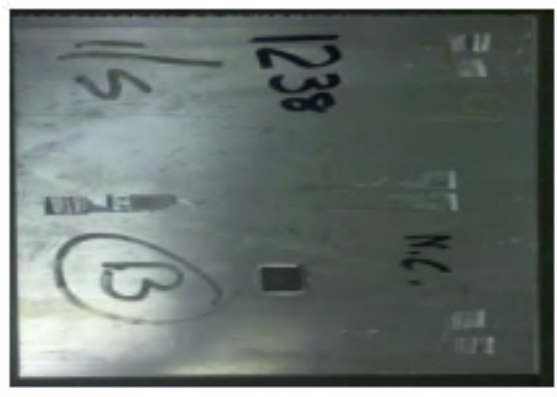

C

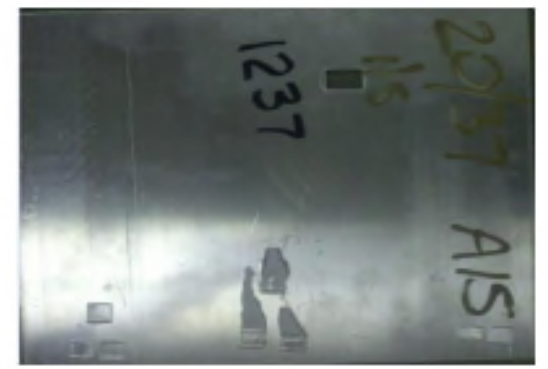

b

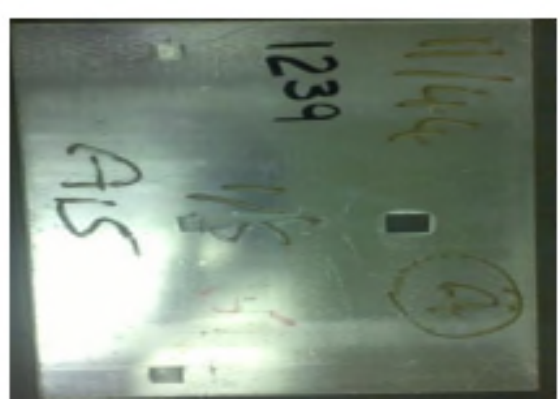

d

Figure 9. Test sample (a) 1236 (b) 1237 (c) 1238 (d) 1239. 
The preliminary test uses a handheld device with permanent magnet sensor. Pair of the sensor is arranged in pitch-catch mode. One of them is a transmitter, and other is a receiver. The sound is generated on the aluminum alloy surface and propagates as a guided wave along the plate and received by the receiver.

Figure 10 shows the comparisons of the signals collected from the edge and middle portion of the sample. The mid-portion indicates poor bonding with peel test, whereas the edge portion indicates good bonding with peel test. The blue line indicates the good region and white line indicates the bad region. Although the slight amplitude change may not be reliable during the in-line test, the shift in time can be accurately measured as an indication of the flaw. The preliminary test indicates that EMAT guided wave technique is very promising for inspection for the bimetal product.

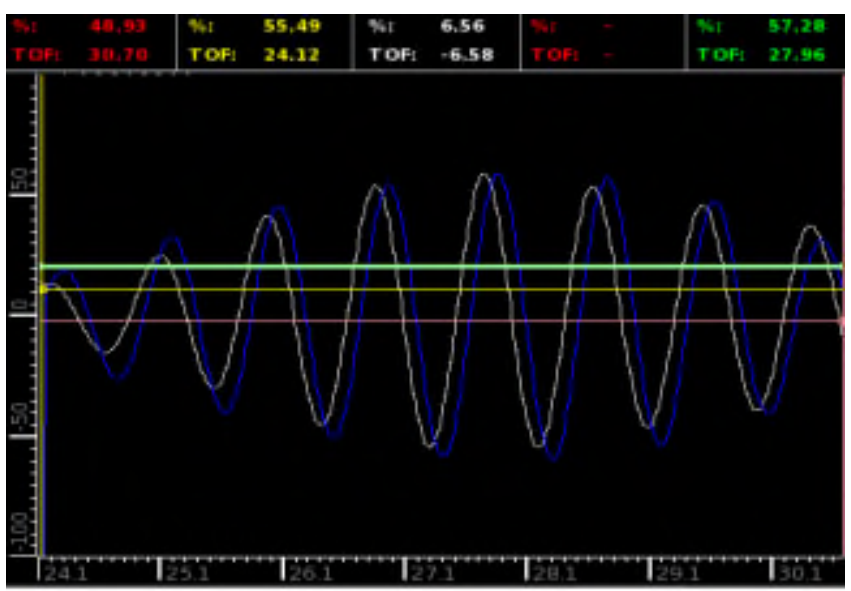

Figure 10. Signal collected in good region (blue) vs. signal collected in bad region (white).

\subsection{NON ULTRASONIC TECHNIQUES}

\subsubsection{Shearography}

Figure 11 represents investigation of adhesive bonded composite assemblies using shearography utilizing multi-frequency vibrational excitation. Dark color represents the accurately bonded area, whereas bright white color indicates areas associated with bond defects [83]. Figure 15 shows two bond lines, debond and various bond defects can be seen. 

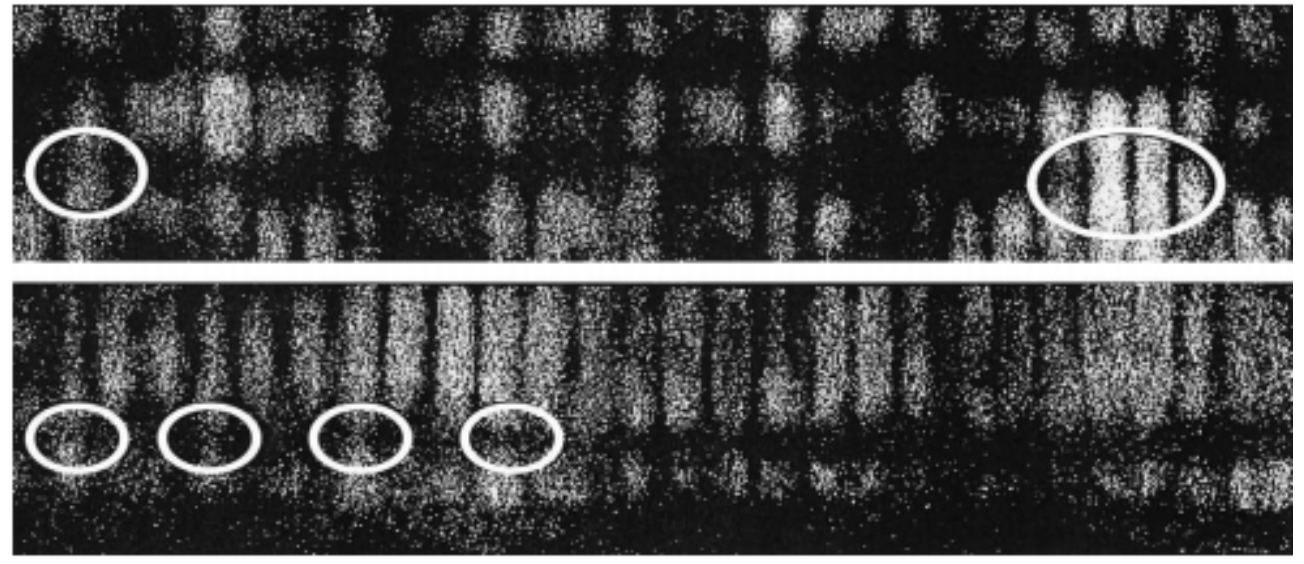

Figure 11. Composite Adhesive Bond Lines Investigation using Shearography [83]

Closed boundaries bond defects can be exposed easily when the load increment used among disclosures is in the form of heating, vacuum stressing or single frequency vibrational excitation. Using vacuum stressing, Figure 12 (a) shows usual small image shearing shearographic fringe patterns of a layered plate structure consisting of square bond defects installed at various depths from illuminated surface. Figure 12 (b) represents the equivalent holographic (equivalent to large-image shearing) fringe patterns.

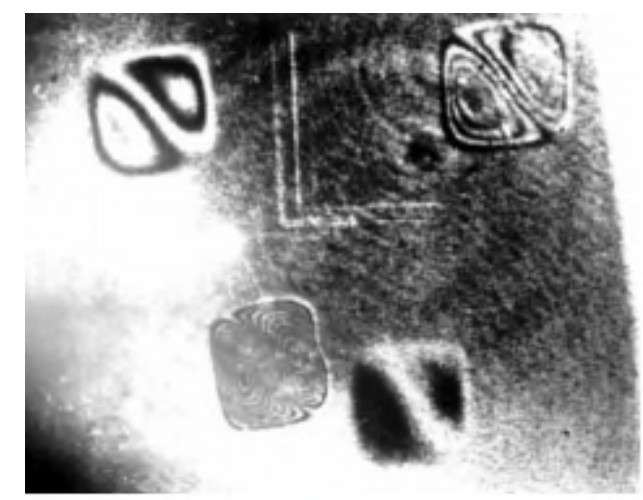

(a)

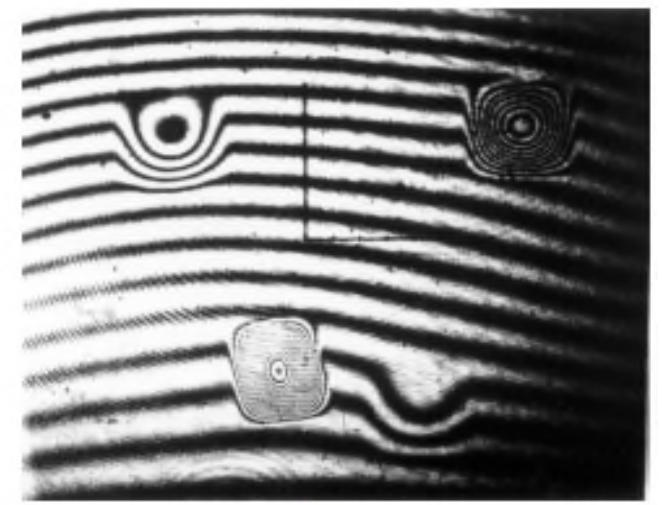

(b)

Figure 12. Usual fringe patterns of a layered plate structure consisting of square bond defects installed at various depths (a) Small Image Shearing Shearographic Fringe Pattern (b) Holographic Fringes due to Large Image Shearing [58].

It can be observed that boundary shape of disturbed fringes is smaller as compared to that of the bond defect. Moreover, the density of the disturbed fringes decreases with increasing depth 
of bond defect and with nonresilient adhesive layers, the boundary of disturbed fringes is almost the same size as the bond defect [58].

\subsubsection{Thermography}

Car bonnet and panel frame structure was used to demonstrate the capability of infrared thermography for analysis of adhesive bond. Results obtained by evaluating panel frame structure are shown in Figure 13. By applying reflection mode of the pulse thermography technique location and dimension of the bond region can be clearly seen as shown in Figure 14. The dark area shows the bonded area for the plate and rod since the heat can flow through the bond area and cooled faster than the bond defect area.

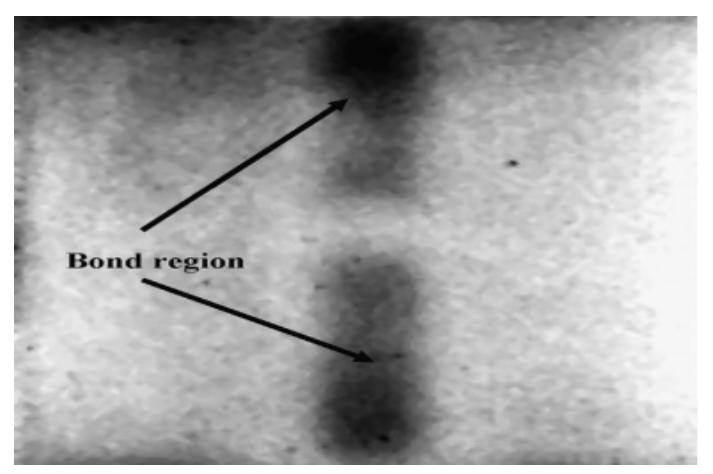

Figure 13. Thermal Image of Adhesive response of Al Plate and Rod after Transient Pulse Thermography [102].

To identify the bond adhesive bond strength using thermography, a CFRP in which aluminum alloy is bonded to surface was studied. The bright region shows the well bonded and dark regions show the unbonded regions [102].

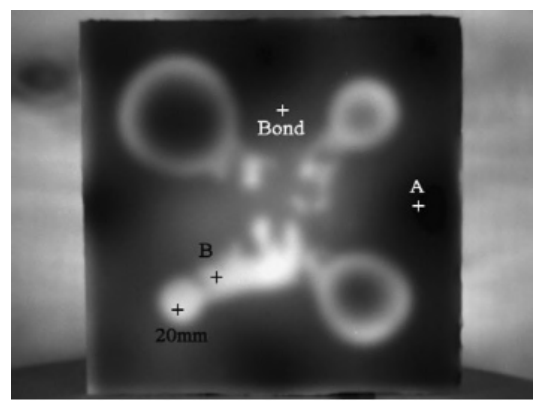

Figure 14. Thermal Image of Al Plate Adhesive with Carbon Fibre Sample with 20mm, $30 \mathrm{~mm}, 40 \mathrm{~mm}$ and 50mm diameter Subsurface Flaws [102]. 
Thermography is a useful technique to identify cracks in Glass Fiber Reinforced Plastics (GFRP) composites, and it can provide effective results in determining various discontinuities such as damage due to impact, inclusions, and voids present in (CFRP) laminates [103].

\section{DISCUSSION FOR SUITABILITY ANALYSIS}

Based on the suitability with respect to disband detection in different NDT techniques, Table 1 and Table 2 ranks these techniques. The ranking criteria is set as: Ideal Application=3, Partially Suitable=2, Not Suitable=1.

Based on these findings, guided waves and EMATs are best ultrasonic techniques while for non-ultrasonic techniques laser shearography is best.

Table 1: Suitability with respect to Disbond detection of ultrasonic techniques and their ranking (3 = Ideal Application, 2 = Partially Suitable, 1 = Not Suitable)

\begin{tabular}{|c|c|c|c|}
\hline \multicolumn{4}{|c|}{ Ultrasonic Techniques } \\
\hline \multirow{3}{*}{ Pulse-Echo } & Characteristics & $\begin{array}{l}\text { Suitability with } \\
\text { respect to Disbond } \\
\text { detection }\end{array}$ & Rank \\
\hline & $\begin{array}{l}\text { - A comparison of test piece signal } \\
\text { amplitude form to the amplitudes } \\
\text { acquired form a reference defines } \\
\text { the discontinuity size. } \\
\text { - Standard depth location of the } \\
\text { flaw by calibrating the horizontal } \\
\text { scale of A-scan display. } \\
\text { - Material properties can be studied } \\
\text { as indicated by relative sound } \\
\text { attenuation or plan velocity } \\
\text { changes of compound items. }\end{array}$ & $\begin{array}{l}\text { Pulse-echo is also very } \\
\text { useful for detecting the } \\
\text { bond strength and can } \\
\text { provide handful details } \\
\text { utilizing C-scan images } \\
\text { developed by using some } \\
\text { custom signal analysis. } \\
\text { Through study on pulse- } \\
\text { echo ultrasonic } \\
\text { successfully illustrated the } \\
\text { fractions of the signal that } \\
\text { had the primary bond } \\
\text { strength detail }\end{array}$ & 2 \\
\hline & $\begin{array}{l}\text { - It is also called obstruction } \\
\text { method due to the reason it } \\
\text { calculates total attenuation of the } \\
\text { material done by feature }\end{array}$ & $\begin{array}{l}\text { Through transmission } \\
\text { ultrasonic technique was } \\
\text { able to identify bond } \\
\text { defects. Evaluation data, }\end{array}$ & 2 \\
\hline
\end{tabular}




\begin{tabular}{|c|c|c|c|}
\hline $\begin{array}{c}\text { Through } \\
\text { Transmission } \\
\text { n }\end{array}$ & $\begin{array}{l}\text { responsible for obscuring the } \\
\text { beam. } \\
\text { - A comparison can be made based } \\
\text { on the attenuation among various } \\
\text { objects and among various } \\
\text { regions of the same object. } \\
\text { - Mostly utilized to develop } \\
\text { attenuation C- scans that detect } \\
\text { most common flaws. } \\
\text { - No 'dead zone' meaning } \\
\text { discontinuities can be found out } \\
\text { at all depths throughout the } \\
\text { thickness of the specimen at the } \\
\text { measurement location. }\end{array}$ & $\begin{array}{l}\text { mostly color coded c- } \\
\text { scans, indicated when the } \\
\text { strength of the bond line } \\
\text { fails. This is important } \\
\text { information that provides } \\
\text { the ability to more } \\
\text { accurately and reliably } \\
\text { accept-reject levels. }\end{array}$ & \\
\hline Guided Waves & $\begin{array}{l}\text { - Long distance evaluation using } \\
\text { single probe position. } \\
\text { - The advantage of generating } \\
\text { surface and guided waves in any } \\
\text { object and material which } \\
\text { includes composite materials } \\
\text { with low wave velocity. } \\
\text { - Higher frequency excitation for } \\
\text { improved sensitivity and } \\
\text { resolution is possible }\end{array}$ & $\begin{array}{l}\text { For thin plate and surface } \\
\text { inspection guided wave is } \\
\text { a natural fit. Rather than } \\
\text { facing a problem with very } \\
\text { high equipment in the } \\
\text { normal beam test, guided } \\
\text { wave test can be } \\
\text { performed at relatively } \\
\text { low-frequency high signal } \\
\text { to noise ratio. Guided } \\
\text { wave moves which proved } \\
\text { sensitive to bonding } \\
\text { quality can be used for the } \\
\text { inspection. }\end{array}$ & 3 \\
\hline $\begin{array}{c}\text { Electromagnetic } \\
\text { Acoustic } \\
\text { Transducers } \\
\text { (EMATs) }\end{array}$ & $\begin{array}{l}\text { - Non-contact inspection. } \\
\text { - Alternative to piezoelectric } \\
\text { transducers dry evaluation. } \\
\text { - Generate sound in an object under } \\
\text { consideration. } \\
\text { - No need of couplant. } \\
\text { - Induce ultrasonic waves into a } \\
\text { test object with two interactive } \\
\text { magnetic fields. }\end{array}$ & $\begin{array}{l}\text { EMAT is an ultrasonic } \\
\text { testing technique having } \\
\text { high repeatability and } \\
\text { reliability and suitable for } \\
\text { automation. Instead of } \\
\text { struggling with the } \\
\text { variation caused by } \\
\text { couplant thickness and } \\
\text { temperature, the sound is } \\
\text { generated by EMAT } \\
\text { transducers on the surface } \\
\text { of the structure. The } \\
\text { process is couplant free. } \\
\text { The inspection is capable }\end{array}$ & 3 \\
\hline
\end{tabular}




\begin{tabular}{|l|l|l|l|}
\hline & & $\begin{array}{l}\text { of meeting the production } \\
\text { throughput speed of 8-15 } \\
\text { meters per minute. }\end{array}$ & \\
\hline
\end{tabular}

Table 2: Suitability with respect to disbond detection of Non- ultrasonic techniques and their ranking (3 = Ideal Application, 2 = Partially Suitable, 1 = Not Suitable)

\begin{tabular}{|c|c|c|c|}
\hline \multicolumn{4}{|c|}{ Non - Ultrasonic Techniques } \\
\hline & Characteristics & $\begin{array}{c}\text { Suitability of } \\
\text { Disbond }\end{array}$ & Rank \\
\hline $\begin{array}{c}\text { Laser } \\
\text { Shearography }\end{array}$ & $\begin{array}{l}\text { - Full Field. } \\
\text { - Contact-free evaluation. } \\
\text { - Calculates mechanical dislocation. } \\
\text { - Methods of loading are vacuum } \\
\text { pressure (partial), thermal shock } \\
\text { excitation and acoustic wave. } \\
\text { - Captures speckle pattern for study. } \\
\text { - The qualitative and quantitative study } \\
\text { can be carried out using the density of } \\
\text { the fringe pattern. }\end{array}$ & $\begin{array}{l}\text { Compared to other } \\
\text { techniques } \\
\text { shearography is } \\
\text { usefully suitable for } \\
\text { the evaluation of } \\
\text { adhesive joints for } \\
\text { identification of } \\
\text { discontinuities. } \\
\text { Shearography under } \\
\text { certain conditions can } \\
\text { be used to identify the } \\
\text { bond strength. } \\
\text { Shearography proved } \\
\text { to be useful in } \\
\text { determining various } \\
\text { discontinuities such as } \\
\text { voids, disbonds } \\
\text { delaminations, etc. } \\
\text { Shearography can } \\
\text { provide excellent } \\
\text { information on } \\
\text { debonds/delaminations } \\
\text { in composite laminates }\end{array}$ & 3 \\
\hline Thermography & $\begin{array}{l}\text { - Full Field. } \\
\text { - Contact-free evaluation. } \\
\text { - Thermal degradation measurement. }\end{array}$ & $\begin{array}{l}\text { It identifies infrared } \\
\text { radiation from the } \\
\text { specimen which can } \\
\text { be used to calculate } \\
\text { the response of surface } \\
\text { temperature to the } \\
\text { thermal excitation. }\end{array}$ & 2 \\
\hline
\end{tabular}




\begin{tabular}{|c|c|c|c|}
\hline & $\begin{array}{l}\text { - Methods of loading are a long heating } \\
\text { pulse, transient pulse excitation, and } \\
\text { induction heating. } \\
\text { - Captures a series of thermal images for } \\
\text { evaluation. } \\
\text { - Qualitative and quantitative evaluation } \\
\text { based on the distribution of temperature } \\
\text { and its transition time. }\end{array}$ & $\begin{array}{l}\text { Thermography } \\
\text { successfully identified } \\
\text { bond defects in the } \\
\text { composites and } \\
\text { provides very useful } \\
\text { information to detect } \\
\text { debonds in the } \\
\text { structures. } \\
\text { Thermography is a } \\
\text { very useful tool and } \\
\text { can be used as } \\
\text { examining tool to } \\
\text { access the health of an } \\
\text { object such as bond } \\
\text { defect strength. }\end{array}$ & \\
\hline Radiography & $\begin{array}{l}\text { - Deploys beams of ionizing radiation to } \\
\text { conduct the NDT of objects. } \\
\text { - Quality and quantity evaluation based } \\
\text { on a comparison of the differences in } \\
\text { density of two materials. }\end{array}$ & $\begin{array}{l}\text { Radiography is the } \\
\text { least effective } \\
\text { technique to detect } \\
\text { flaws such as } \\
\text { disbands, which can } \\
\text { be found parallel to } \\
\text { the surface under } \\
\text { investigation. } \\
\text { Conventional } \\
\text { radiography cannot } \\
\text { detect flaws that have } \\
\text { low depth in the } \\
\text { direction of the beam. } \\
\text { Cracks lying parallel } \\
\text { to the radiation beam } \\
\text { can be detected. For } \\
\text { the same purpose, } \\
\text { delamination that is } \\
\text { perpendicular to the } \\
\text { beam is very difficult } \\
\text { to detect using } \\
\text { traditional } \\
\text { radiography. }\end{array}$ & 1 \\
\hline
\end{tabular}

\section{CONCLUSION}

The suitability's of all these novel NDT techniques shows that the advanced ultrasonic proved to be more efficient and reliable, especially in the detection of bond defects. The guided wave EMATs are very sensitive for detecting bond defects and can provide a handful of information. 
Through transmission ultrasonic technique detected the bond defects. Evaluation data, mostly color coded c - scans, indicated when the strength of the bond line fails. Pulse-echo is also very useful for detecting the bond strength and can provide handful details utilizing C-scan images developed by using some custom signal analysis.

Shearography is widely used as a non-destructive testing technique and is already accepted as useful industrial NDT tool. It can provide precious information about debonds in laminate composites. It has the desirable features of being non-contact, full field, no reference beam required and uses very stable environment. Thermography also proved to be very effective for detecting flaws such as delaminations, cracks and bond defects in materials. Results have shown that thermography provides useful results for detecting relevant defects in the materials.

Ultrasonic techniques, such as Pulse Echo, Through Transmission, Guided Waves and EMATs proved to be very effective for detecting disbonds in the different materials. Non-ultrasonic techniques, such as Laser Shearography and Thermography also gave promising results to demonstrate the condition of the bond. Ultrasonic techniques provided better results in order to find out the bond strength compared to Non-ultrasonic techniques, while Guided waves and EMATs are the best techniques for detecting the relevant defects in the materials.

\section{Conflict of Interest:}

The authors declare that they have no conflict of interest.

\section{References}

1. Yao, L., et al., Bridging effect on mode I fatigue delamination behavior in composite laminates. Composites Part A: Applied Science and Manufacturing, 2014. 63: p. 103-109.

2. Chen, J.-F., E.V. Morozov, and K. Shankar, Simulating progressive failure of composite laminates including in-ply and delamination damage effects. Composites Part A: Applied Science and Manufacturing, 2014. 61: p. 185-200.

3. Aslan, Z. and M. Şahin, Buckling behavior and compressive failure of composite laminates containing multiple large delaminations. Composite Structures, 2009. 89(3): p. 382-390.

4. Landry, B. and G. LaPlante, Modeling delamination growth in composites under fatigue loadings of varying amplitudes. Composites Part B: Engineering, 2012. 43(2): p. 533-541.

5. Naghipour, P., M. Bartsch, and H. Voggenreiter, Simulation and experimental validation of mixed mode delamination in multidirectional CF/PEEK laminates under fatigue loading. International Journal of Solids and Structures, 2011. 48(6): p. 1070-1081.

6. Turon, A., et al., Simulation of delamination in composites under high-cycle fatigue. Composites Part A: Applied Science and Manufacturing, 2007. 38(11): p. 2270-2282.

7. Hojo, M., et al., Effect of stress ratio on near-threshold propagation of delimination fatigue cracks in unidirectional CFRP. Composites Science and Technology, 1987. 29(4): p. 273-292. 
8. Shahverdi, M., A.P. Vassilopoulos, and T. Keller, Experimental investigation of R-ratio effects on fatigue crack growth of adhesively-bonded pultruded GFRP DCB joints under CA loading. Composites Part A: Applied Science and Manufacturing, 2012. 43(10): p. 1689-1697.

9. Argüelles, A., et al., Interlaminar crack initiation and growth rate in a carbon-fibre epoxy composite under mode-l fatigue loading. Composites Science and Technology, 2008. 68(12): p. 2325-2331.

10. Hojo, M., et al., Mode I delamination fatigue properties of interlayer-toughened CF/epoxy laminates. Composites Science and Technology, 2006. 66(5): p. 665-675.

11. Shivakumar, K., et al., A total fatigue life model for mode I delaminated composite laminates. International Journal of Fatigue, 2006. 28(1): p. 33-42.

12. Coronado, P., et al., Influence of temperature on a carbon-fibre epoxy composite subjected to static and fatigue loading under mode-I delamination. International Journal of Solids and Structures, 2012. 49(21): p. 2934-2940.

13. Shahverdi, M., A.P. Vassilopoulos, and T. Keller, A total fatigue life model for the prediction of the R-ratio effects on fatigue crack growth of adhesively-bonded pultruded GFRP DCB joints. Composites Part A: Applied Science and Manufacturing, 2012. 43(10): p. 1783-1790.

14. Rans, C., R. Alderliesten, and R. Benedictus, Misinterpreting the results: How similitude can improve our understanding of fatigue delamination growth. Composites Science and Technology, 2011. 71(2): p. 230-238.

15. Ibrahim, M.E., Nondestructive evaluation of thick-section composites and sandwich structures: A review. Composites Part A: Applied Science and Manufacturing, 2014. 64: p. 36-48.

16. Yang, S., L. Gu, and R.F. Gibson, Nondestructive detection of weak joints in adhesively bonded composite structures. Composite Structures, 2001. 51(1): p. 63-71.

17. Schliekelmann, R.J., Non-destructive testing of adhesive bonded metal-to-metal joints 1. NonDestructive Testing, 1972. 5(2): p. 79-86.

18. Rokhlin, S., M. Hefets, and M. Rosen, An elastic interface wave guided by a thin film between two solids. Journal of Applied Physics, 1980. 51(7): p. 3579-3582.

19. Rokhlin, S.I., An ultrasonic bridge for the study of viscoelastic properties of thin interface films. The Journal of the Acoustical Society of America, 1983. 73(5): p. 1619-1623.

20. Rokhlin, S.I., A.I. Lavrentyev, and B. Li, Ultrasonic evaluation of environmental durability of adhesive joints. Research in Nondestructive Evaluation, 1993. 5(2): p. 95-109.

21. Rokhlin, S.I. and D. Marom, Study of adhesive bonds using low-frequency obliquely incident ultrasonic waves. The Journal of the Acoustical Society of America, 1986. 80(2): p. 585-590.

22. Pilarski, A. and J.L. Rose, A transverse-wave ultrasonic oblique-incidence technique for interfacial weakness detection in adhesive bonds. Journal of Applied Physics, 1988. 63(2): p. 300-307.

23. Nagy, P.B. and L. Adler, Interface Characterization by True Guided Modes, in Review of Progress in Quantitative Nondestructive Evaluation: Volume 10B, D.O. Thompson and D.E. Chimenti, Editors. 1991, Springer US: Boston, MA. p. 1295-1302.

24. Wang, W. and S.I. Rokhlin, Evaluation of interfacial properties in adhesive joints of aluminum alloys using angle-beam ultrasonic spectroscopy. Journal of Adhesion Science and Technology, 1991. 5(8): p. 647-666.

25. Dickstein, P.A., et al., Ultrasonic feature-based classification of the interfacial condition in composite adhesive joints. Research in Nondestructive Evaluation, 1990. 2(4): p. 207-224.

26. Kwon, O.-Y. and S.-H. Lee, Acousto-ultrasonic evaluation of adhesively bonded CFRP-aluminum joints. NDT \& E International, 1999. 32(3): p. 153-160.

27. Kim, K.-S., et al., Failure mode and strength of uni-directional composite single lap bonded joints with different bonding methods. Composite Structures, 2006. 72(4): p. 477-485.

28. Schroeder, J.A., et al., Non-destructive testing of structural composites and adhesively bonded composite joints: pulsed thermography. Composites Part A: Applied Science and Manufacturing, 2002. 33(11): p. 1511-1517. 
29. Vijaya Kumar, R.L., M.R. Bhat, and C.R.L. Murthy, Evaluation of kissing bond in composite adhesive lap joints using digital image correlation: Preliminary studies. International Journal of Adhesion and Adhesives, 2013. 42: p. 60-68.

30. Vine, K., P. Cawley, and A.J. Kinloch, The Correlation of Non-Destructive Measurements and Toughness Changes in Adhesive Joints during Environmental Attack. The Journal of Adhesion, 2001. 77(2): p. 125-161.

31. Lavrentyev, A.I. and S.I. Rokhlin, Ultrasonic spectroscopy of imperfect contact interfaces between a layer and two solids. The Journal of the Acoustical Society of America, 1998. 103(2): p. 657-664.

32. Brotherhood, C.J., B.W. Drinkwater, and F.J. Guild, The Effect of Compressive Loading on the Ultrasonic Detectability of Kissing Bonds in Adhesive Joints. Journal of Nondestructive Evaluation, 2002. 21(3): p. 95-104.

33. Poveromo, S.L. and J.C. Earthman, Analysis of "Kiss" Bonds Between Composite Laminates. JOM, 2014. 66(6): p. 970-978.

34. Teles, S.V. and D.E. Chimenti, Closed disbond detection in marine glass-epoxy/balsa composites. NDT \& E International, 2008. 41(2): p. 129-136.

35. Yan, D., S.A. Neild, and B.W. Drinkwater, Modelling and measurement of the nonlinear behaviour of kissing bonds in adhesive joints. NDT \& E International, 2012. 47(Supplement C): p. 18-25.

36. Ohara, Y., T. Mihara, and K. Yamanaka, Effect of adhesion force between crack planes on subharmonic and DC responses in nonlinear ultrasound. Ultrasonics, 2006. 44(2): p. 194-199.

37. Solodov, I. and G. Busse, Nonlinear air-coupled emission: The signature to reveal and image microdamage in solid materials. Applied Physics Letters, 2007. 91(25): p. 251910.

38. Yan, D., B.W. Drinkwater, and S.A. Neild, Measurement of the ultrasonic nonlinearity of kissing bonds in adhesive joints. NDT \& E International, 2009. 42(5): p. 459-466.

39. Chen, B.-Y., et al., A vibro-acoustic modulation method for the detection of delamination and kissing bond in composites. Journal of Composite Materials, 2016. 50(22): p. 3089-3104.

40. Pérez, M.A., et al., Comparative experimental analysis of the effect caused by artificial and real induced damage in composite laminates. Composite Structures, 2014. 112: p. 169-178.

41. Breysse, D., et al., How to combine several non-destructive techniques for a better assessment of concrete structures. Cement and Concrete Research, 2008. 38(6): p. 783-793.

42. Schliekelmann, R.J., Non-destructive testing of adhesive bonded metal-to-metal joints 1. 1972. p. 79-86.

43. Dukes, W.A. and A.J. Kinloch, Non-destructive testing of bonded joints. Non-Destructive Testing, 1974. 7(6): p. 324-326.

44. JL, R., E, Segal, Nondestructive testing of adhesive bond joints. Research techniques in nondestructive testing 1980. 4: p. 275-315.

45. Guyott, C.C.H., P. Cawley, and R.D. Adams, The Non-destructive Testing of Adhesively Bonded Structure: A Review. The Journal of Adhesion, 1986. 20(2): p. 129-159.

46. RD, A., Testing of bonded joints. . Applied Science publishers Ltd, 1987: p. 68-151.

47. Adams, R.D. and P. Cawley, A review of defect types and nondestructive testing techniques for composites and bonded joints. NDT International, 1988. 21(4): p. 208-222.

48. Adams, R.D., The nondestructive evaluation of bonded structures. Construction and Building Materials, 1990. 4(1): p. 3-8.

49. Savage, G., Failure prevention in bonded joints on primary load bearing structures. Engineering Failure Analysis, 2007. 14(2): p. 321-348.

50. Nagy, P.B., Ultrasonic classification of imperfect interfaces. Journal of Nondestructive Evaluation, 1992. 11(3): p. 127-139.

51. Jiao, D. and J.L. Rose, An ultrasonic interface layer model for bond evaluation. Journal of Adhesion Science and Technology, 1991. 5(8): p. 631-646. 
52. EHRHART, B., VALESKE, Bernd., MULLER, Charles-Edouard., BOCKENHEIMER, Methods for the Quality Assessment of Adhesive Bonded CFRP Structures - A Resumé, in NDT in Aerospace 2010. p. 1-9.

53. R. Murayama., K., Fujisawa., H, Fukuoka., M. Hirao NDT \& E International, 1996. 29.

54. R. Murayama., K., Fujisawa., H, Fukuoka., M. Hirao, 1997. 30(141).

55. T. D'Orazio., M., Leo., A, Distnace., C, Guaragnella., V, Pianese., G, Cavaccini, NDT \& E International, 2008. 41.

56. O, K., M. Dorian., S, Tetsuo., S, Minoru., H, Hideo, NDT \& E International, 1999. 32: p. 177.

57. X.P, M., Nondestructive Evaluation of Materials by Infrared Thermography. Springer-Verlag, 1993.

58. Hung, Y.Y., et al., Evaluating the soundness of bonding using shearography. Composite Structures, 2000. 50(4): p. 353-362.

59. Kapadia, A., Non-Destructive Testing of Composite Materials Germany. p. 1-48.

60. Mouritz, A.P., C. Townsend, and M.Z. Shah Khan, Non-destructive detection of fatigue damage in thick composites by pulse-echo ultrasonics. Composites Science and Technology, 2000. 60(1): p. 23-32.

61. Allin, J.M., Disbond Detection in Adhesive Joints Using Low - Frequency Ultrasound 2002, University of London.

62. Rokhlin, S.I. and Y.J. Wang, Analysis of boundary conditions for elastic wave interaction with an interface between two solids. The Journal of the Acoustical Society of America, 1991. 89(2): p. 503-515.

63. Xu, P.C. and S.K. Datta, Guided waves in a bonded plate: A parametric study. Journal of Applied Physics, 1990. 67(11): p. 6779-6786.

64. Kundu, T. and K. Maslov, Material interface inspection by lamb waves. International Journal of Solids and Structures, 1997. 34(29): p. 3885-3901.

65. Kundu, T., et al., Detection of kissing bonds by Lamb waves. Ultrasonics, 1998. 35(8): p. 573580.

66. Dalton, R.P., P. Cawley, and M.J.S. Lowe, The Potential of Guided Waves for Monitoring Large Areas of Metallic Aircraft Fuselage Structure. Journal of Nondestructive Evaluation, 2001. 20(1): p. 29-46.

67. Drinkwater, B.W., M. Castaings, and B. Hosten, The measurement of AO and SO lamb wave attenuation to determine the normal and shear stiffnesses of a compressively loaded interface. J Acoust Soc Am, 2003. 113(6): p. 3161-70.

68. Croxford, A.J., et al., Efficient temperature compensation strategies for guided wave structural health monitoring. Ultrasonics, 2010. 50(4): p. 517-528.

69. Balvantín, A., A. Baltazar, and J.I. Aranda-Sanchez, A study of guided wave propagation on a plate between two solid bodies with imperfect boundary conditions. International Journal of Mechanical Sciences, 2012. 63(1): p. 66-73.

70. Maxfield, B., Fortunko CM The design and use of electromagnetic acoustic wave transducers(EMATS). Material Evaluation 1983. 41: p. 1399-408.

71. Alers, G., Bums, LR, EMAT designs for special applications. Material Evaluation, 1987. 45: p. 1148-9.

72. maxfield, B., Kurmoto A., Hulbert, JK, The design and use of electromagnetic acoustic wave transducers(EMATs) Material Evaluation, 1983. 45(10): p. 1166-83.

73. Silk, M., Electromagnetic acoustic transducers. Ultrasonic transducers for nondestructive testing, 1984: p. 111-119.

74. Dobbs, E.R., Electromagnetic generation of ultrasonic waves in metals. Journal of Physics and Chemistry of Solids, 1970. 31(8): p. 1657-1667.

75. Masahiko, H., Hirstsugu, Ogi, EMATs for science and industry-non contacting ultrasonic measurements. 2003: Kluwer Academic Publishers 
76. Lopez, B., Weld Inspection with EMAT Using Guided Waves The e-Journal of Nondestructive Testing, 2008: p. 1-5.

77. Huang, S., et al., Study on the lift-off effect of EMAT. Sensors and Actuators A: Physical, 2009. 153(2): p. 218-221.

78. Lopez, B., Weld Inspection with EMAT Using Guided Waves The e-Journal of Nondestructive Testing 2008: p. 1-5.

79. Liu, Z., et al., NDT capability of digital shearography for different materials. Optics and Lasers in Engineering, 2011. 49(12): p. 1462-1469.

80. Hung, Y.Y., A speckle-shearing interferometer: a tool for measuring derivatives of surface displacement. Opt Commun, 1974. 2: p. 132-5.

81. Hung, Y.Y., Nondestructive evaluation by electronic shearography, in Sixteenth symposium on nondestructive evaluation. 1987: San Antinio, Texas.

82. Huang, J.R., H.D. Ford, and R.P. Tatam, Slope measurement by two-wavelength electronic shearography. Optics and Lasers in Engineering, 1997. 27(3): p. 321-333.

83. Hung, Y.Y. and H.P. Ho, Shearography: An optical measurement technique and applications. Materials Science and Engineering: R: Reports, 2005. 49(3): p. 61-87.

84. Hung, Y.Y. and J.Q. Wang, Dual-beam phase shift shearography for measurement of in-plane strains. Optics and Lasers in Engineering, 1996. 24(5): p. 403-413.

85. Leendertz, J.A. and J.N. Butters, An image-shearing speckle-pattern interferometer for measuring bending moments. Journal of Physics E: Scientific Instruments, 1973. 6(11): p. 1107.

86. Creath, K. and J. Schmit, N-point spatial phase-measurement techniques for non-destructive testing. Optics and Lasers in Engineering, 1996. 24(5): p. 365-379.

87. Fornaro, G., Franceschetti, G., Lanari R, Interferometric SAR phase unwrapping using Green's formulation. IEEE Trans Geosci Remote Sensing. 34(3): p. 720-7.

88. JW, N., NDT Shearography. Aerosp Test Int, 2007. 93.

89. <Aerospace NDT with Advanced Laser Shearography_534.pdf>.

90. Francis, D., R.P. Tatam, and R.M. Groves, Shearography technology and applications: a review. Measurement Science and Technology, 2010. 21(10): p. 102001.

91. Kuhn, E., E. Valot, and P. Herve, A comparison between thermosonics and thermography for delamination detection in polymer matrix laminates. Composite Structures, 2012. 94(3): p. 1155-1164.

92. Zhu, Y.K., et al., A review of optical NDT technologies. Sensors (Basel), 2011. 11(8): p. 7773-98.

93. Mignogna, R.B., et al., Thermographic investigation of high-power ultrasonic heating in materials. Ultrasonics, 1981. 19(4): p. 159-163.

94. Rantala, J., D. Wu, and G. Busse, Amplitude-modulated lock-in vibrothermography for NDE of polymers and composites. Research in Nondestructive Evaluation, 1996. 7(4): p. 215-228.

95. Favro, L.D., et al., Infrared imaging of defects heated by a sonic pulse. Review of Scientific Instruments, 2000. 71(6): p. 2418-2421.

96. McMaster, R., McIntire, P., Mester, ML., Moore, PO, Special nondestructive testing methods. Nondestructive Testing Handbook. Vol. 9. 1995: Columbus (OH).

97. Maldague, X., Infrared technology for nondestructive testing. 2001.

98. Krapez, J.-C. and P. Cielo, Thermographic nondestructive evaluation: Data inversion procedures. Research in Nondestructive Evaluation, 1991. 3(2): p. 81-100.

99. Favro, L.D., et al. Imaging the early time behavior of reflected thermal wave pulses. 1995.

100. Déom, A.A., D. Boscher, and D.L. Balageas, Pulsed Photothermal Nondestructive Testing Application to Carbon Epoxy Laminates, in Review of Progress in Quantitative Nondestructive Evaluation, D.O. Thompson and D.E. Chimenti, Editors. 1990, Springer US: Boston, MA. p. 525531.

101. Roach, D., Rackow, Kirk., Duvall, Randy., , Innovative Use of Adhesive Interface Characteristics to Nondestructively Quantify the Strength of Bonded Joints 2005, FAA Airworthiness Assurance Center USA. 
102. Hung, Y.Y., et al., Review and comparison of shearography and active thermography for nondestructive evaluation. Materials Science and Engineering: R: Reports, 2009. 64(5): p. 73112.

103. Pinto, F., F.Y. Maroun, and M. Meo, Material enabled thermography. NDT \& E International, 2014. 67: p. 1-9. 
2018-03-29

\title{
Identification of an effective
} nondestructive technique for bond defect determination in laminate composites - a technical review

\author{
Asif, Muhammad
}

SAGE

Muhammad A, Khan MA, Khan SZ, et al., (2018) Identification of an effective nondestructive technique for bond defect determination in laminate composites - a technical review. Journal of Composite Materials, Volume 52, Issue 26, November 2018, pp. 3589-3599

https://doi.org/10.1177/0021998318766595

Downloaded from Cranfield Library Services E-Repository 